\title{
A Short History of Documenting Spiritual Care
}

\author{
Simon Peng-Keller and David Neuhold
}

On January 5, 1972, Frère Roger, founder and prior of the Taizé Community, noted down: "I want to pick up my diary again. There is no substitute for writing, this slow reflection, in which I record my efforts and insights in rounded letters on the page that shines in the light of the lamp" (Schutz 1974, 116). Writing notes on his experiences as a spiritual companion and leader served as an instrument of spiritual selfcare. In his daily notes, Frère Roger reflected upon experiences, encounters, and decisions. Nonetheless, his writing was in the service of memory - his own as well as that of others. Recording his "efforts and knowledge" was a form of witnessing and pastoral care. Written "in rounded characters on the page that shines in the light of the lamp," Frère Roger's notes are situated in pre-digital modernity. The spiritual caregivers on whom this book focuses and for whom it is written type their notes on keyboards which transmit them to illuminated screens. Their medium, context, and addressees differ from those of Frère Roger. But in one central respect, they take up his experience: in the written retracing of spiritual accompaniment.

Although Frère Roger's documentation practice belongs to the modern age, it resembles forms that have been cultivated in the Christian tradition for centuries. In the following pages, the long history of spiritual documentation, from its very beginnings to the present day, which lives on in recent history, will be brought to mind. Referring to ancient and early modern practices as well as on the developments in the twentieth and twenty-first centuries, we outline a genealogy of charting spiritual care. Historical knowledge affords the possibility of distancing oneself from current ambivalences and quandaries. And sometimes it opens up new perspectives for future development.

\footnotetext{
S. Peng-Keller $(\square)$

Spiritual Care, University of Zurich, Zurich, Switzerland

e-mail: simon.peng-keller@uzh.ch

D. Neuhold

University of Zurich, Zurich, Switzerland 
Historically, literacy has been an agent of change. As Egyptologist Jan Assmann puts it: "Writing is a technology that makes cultural creations possible that would otherwise never exist, and that preserves cultural creations in memory, making accessible to later recourse what would otherwise be forgotten and have vanished" (Assmann 2012, 380). Without writing, there are no postaxial "world" religions and no healthcare chaplaincy. From the very beginning, the extension of communication through external (i.e., written) storage has had a flip side as well: "As with all the more complex instruments, writing [...] gives rise to a dialectic of expansion and loss," Assmann states; since "as an externalized memory, it facilitates a hitherto undreamed-of expansion in our capacity to store and retrieve information and other forms of communication, while simultaneously leading to a shrinkage of our natural memory bank" (Assmann 2011, 9).

Healthcare chaplains struggle with their own version of this dialectic, which is nothing new for religions with a great affinity to writing and reading. In the evolution of Christian spiritual care, there has been, again and again, a strong desire to make systematic records. Writing raises the meaning of life experiences to a new hermeneutic level of reflection. Whereas Frère Roger or Georges Bernanos' diarywriting country priest was emblematic of the twentieth century, healthcare chaplains' writing entries into the ward office computer might play a similar role for spiritual care in the early twenty-first century.

Taking notes in the service of spiritual (self-) care has a long and complex history. As the quotation from Frère Roger's diary shows and as we will outline in more detail, this practice serves at least three purposes: First, it fosters awareness and reflexivity; second, it supports the memory; and, third, it facilitates communication. Our genealogical approach is divided into four sections:

(1) Historical antecedents: Note-writing in Christian spirituality

(2) Note-writing in Clinical Pastoral Education of the twentieth century

(3) Charting spiritual care in electronic medical records (EMRs)

(4) Worldwide distribution

\section{Historical Antecedents: Writing Notes and Christian Spirituality}

In order to shorten the long prehistory of the practices studied in this volume, we concentrate on two typical forms of note-taking in Christian spirituality. While the first one, mentioned in Athanasius' Vita Sancti Antonii (Athanasius, ed. Deferrari 1981) about 360 A. D., was intended for spiritual self-care, the second example, to be found in the "Roman" structured Jesuit order (Friedrich 2007), focused on the spiritual guidance of a large community. In both cases, writing was connected with remembrance (of past events), reflection (about events in the past and present), and recording (for the future). While note-taking in the first case was a form of accounting for oneself, in the second example, it was more concerned with the 
administration of a collective. In these two cases, we can see the poles of a broad spectrum: at one pole, notes are taken for the purpose of self-examination and spiritual growth. At the other, note-taking serves institutional purposes.

The spiritual practice of recording, to which Athanasius bears witness, was in all probability inspired by Stoic philosophers who recommended written self-reflection. According to the analyses of Michael Foucault, this practice, refined in the first and second centuries A.D., had an "ethopoietic" function (Foucault 1997, 207-222). In collecting the mind, it fosters meditative self-awareness and transforms the insights gained into practical knowledge. Christian ascetics and hermits like Antonius continued this practice in their own way. The pioneer of all desert fathers, Athanasius reports, invited his followers: "Let us note and write down our deeds and the movements of our soul as if we were to tell them to each other" (Athanasius, Chapter 55, ed. Deferrari 1981, 185). Self-perception through writing presents itself as a spiritual therapeutic process. The written text becomes a counterpart and mirror. Writing serves the ascetic goal: clearing the mind from distracting thoughts and opening it for contemplation.

More than 1000 years later, the former soldier Ignatius of Loyola also attached central importance to spiritual writing. His spiritual life started with an eremitic period and with experiences similar to those of Antonius. The ideas he later systematized in his Spiritual Exercises had their origins in his spiritual self-care which included written self-reflections. Later in his career, Ignatius became the "superior general" of an expanding order. Like a Calvin in Geneva or a Bullinger in Zurich, he established an extensive bureaucracy and, importantly for us, a refined system of documentation. His successors continued this model, in which systematic recording and the steady flow of information played an important role. Over time, an information management system was established which encompassed comprehensive and centralist standards. This can be seen, for example, in the personnel catalogues of the Society of Jesus itself, where "evaluation templates" for the identification of different characteristics and qualities of members of the order were common. This was implemented by means of short descriptors ("bene," "valde," "optime," etc.) not dissimilar to those used in current "gap texts" or click boxes. Markus Friedrich states in this context: "The assessment of individuals was thus based on a standardized scale" (Friedrich 2007, 69).

The spiritual guidance administrated by sophisticated documentation procedures is more reminiscent of what Foucault described as pastoral power than of an individualized spiritual care. To put it mildly: "[...] the border between 'administrative' and 'edifying' (or: religious) communication was often blurred" (Friedrich 2007, 69). Weighing the different aspects of this documentation practice against each other, Friedrich concludes: "And, of course, for the Jesuits, the efficient organization and administration of their own social body was, in the end, a deeply religious task. They thought about their social body in secular (i.e. administrative) terms, but all for the sake of a religious goal. It might be the ability to combine both perspectives that made the Society of Jesus a successful global player" (Friedrich 2007, 72-73). The success of the Jesuit order can be explained by the combination of different factors. Documentation with ink is one of them. 
While Antonius advocated spiritual self-care through writing in an eremitic desert context, Ignatius and his successors were engaged in the successful administration of a global enterprise for which written documentation and communication were crucial. However, writing for self-care and recording for and about others shouldn't be seen as opposing phenomena. As Frère Roger reminds us, the same practice can serve distinctive ends.

\section{Note-Writing in Clinical Pastoral Education of the Twentieth Century}

With the rise of Clinical Pastoral Education, a new chapter opens up in the history of note-taking for pastoral purposes. This new development took shape in the first decade of the twentieth century in the context of the Emmanuel Movement. It was initiated in Boston by the theologian Elwood Worcester and was influenced by the psychology of William James and Wilhelm Wundt as well as by the New Thought (Hart and Div 2010, 541-542). This Christian pioneer movement, active during the years 1906-1929, started with the aim of providing social and medical support to patients with tuberculosis. Incrementally, the focus turned to nervous disorders and alcoholism, and the spectrum of therapeutical approaches used likewise broadened. Medical instruction as well as psychological and psychotherapeutic approaches (e.g., suggestion, hypnosis) were combined with spiritual support (e.g., confession, prayer, counseling). There was an outpatient service for individual and group therapy connected to the Emmanuel Church, a Presbyterian parish church - hence the name. Interprofessional cooperation was sought and promoted.

To ensure good therapy, it was important for Worcester and his medical colleagues that "pain of all kinds" were diagnosed in the course of treatment, and the "preservation of records, without which no treatment can be regarded as scientific or even safe," was seen as constitutive. The records written by pastors or chaplains were considered essential. For the sake of those in therapy with the Emmanuel Movement, the documentation system of the Massachusetts General Hospital was adopted - "supplemented by notes on the moral and spiritual advice given and on the effect of this advice" (Worcester et al. 1908, 6). Since its foundation in 1821, the Massachusetts General Hospital had played a pioneering role in clinical documentation in general (Gillum 2013, 854). According to Worcester and his colleagues, the collection of information on patients - including spiritual course notes - explicitly served to track the ongoing therapy of people with "nervous disorders" as successfully as possible. The reuse of records was therefore implicitly taken into consideration and regarded as indispensable in and for the therapeutic process.

Although the Emmanuel Movement was a temporary experiment, it inspired further initiatives, especially the Clinical Pastoral Education movement (CPE). The CPE, which started in 1925 in Boston, was linked to that movement, both ideologically and personally. The hematologist Richard Cabot, co-founder of the CPE, was 
one of the doctors who supported the Emmanuel Movement from the beginning (Hendrick 1914, 410-417). According to Cabot, the spiritual dimension should be included in interprofessional care: clinically trained chaplains should be part of the treatment team and document their experiences in medical records. Right from the beginning, the CPE encompassed forms of note-taking for at least three different purposes: for personal reflection, supervision, and interprofessional communication. While the pioneers of the CPE agreed that written documentation was an essential part of a chaplain's professional role, they had different ideas about how this should be done. Remarkably, these differences mirrored distinctive visions concerning the main task of healthcare chaplaincy. From his medical perspective, Cabot saw the duty of chaplains as consisting in the provision of religious and moral support. Anton Boisen's vision of chaplaincy was more ambitious: he was convinced that chaplains also have a scientific and therapeutic task. He therefore emphasized the hermeneutical function of "careful recordkeeping as means to a "more conscious and intelligent [religion] capable of verification and transmission"' (Myers-Shirk $2009,33)$. In order to understand the "living human documents" entrusted to their care, chaplains need the medium of written documents.

An elaborate description of the different applications of note-taking is to be found in the volume The Art of Ministering To The Sick, which Cabot published in 1936 together with the pastor Russell L. Dicks (1906-1965). This publication aimed to close a gap at the interface of religion and medicine by opening up new interdisciplinary horizons. Both authors attribute a decisive role to the written documentation of "ministry," i.e., chaplaincy (cf. Cabot and Dicks 1936, especially chapter "Note-Writing" in part IV "Methods," 244-261). In conclusion, both stated that anyone not writing notes to accompany his work was not suitable for an assignment as hospital chaplain. Expressing it the other way round, in a somewhat gentler formulation, Cabot and Dicks state: "It is inconceivable to us that any conscientious minister can omit writing notes in some form or other" (Cabot and Dicks 1936, 269). Without note-taking, no professional chaplaincy.

Cabot and Dicks focused strongly on the creative power of writing. As in antique self-care, writing notes would have a spiritual function. It can be seen a "spiritual exercise" (Cabot and Dicks 1936, 261). Documentation enables a chaplain to develop further his own work and even to capture something of the transcendent. "Note-writing finds holes and plans to fill them up. It is self-criticism. It is selfrevelation. It is preparation for self-improvement" (Cabot and Dicks 1936, 248). In an environment where chaplains are constantly interacting with doctors, such records provide the badge of professionalism. In their book, both authors are more interested in writing for personal usage. Although interprofessional aspects are touched upon ${ }^{1}$ and a strong patient orientation is presented, the chaplain himself is in the central field of vision. "Note-writing" serves not only to monitor one's own

\footnotetext{
${ }^{1}$ The interprofessional side will then be more strongly integrated within Russell Dicks' "Standards for the Work of the Chaplain in the General Hospital" (1940), especially in point 4. Text taken from www.professionalchaplains.org/files/professional_standards/standards_of_practice/standards_ for_work_of_chaplain_russell_dicks.pdf (without page numbers).
} 
work. It is first and foremost a creative process. It opens up new issues and leads to important insights.

In 1940, four years after The Art of Ministering To The Sick, Dicks published his "Standards for the Work of the Chaplain in the General Hospital" (Dicks 1940). This programmatic paper includes a paragraph on recording. Dicks distinguishes here between three main forms ${ }^{2}$, daily records "which the chaplain keeps for his own use as a check against his memory"; more detailed records "used especially in difficult assignments to help objectify the patient's need in the chaplain's mind and to show him the mistakes and failures he has made in his work"; and finally notes "in the clinical or medical record itself" for interprofessional communication:

This is a brief note, similar to that which the consultant writes, which is simply a record of the chaplain's impression of the patient. The chaplain often discovers significant things about a patient which the physician needs to know; these discoveries as well as impressions should be available in the record. Such a note does not reveal confidences which may have been shared with the chaplain nor does it, in any way, infringe upon the sacred nature of the confessional (Dicks 1940, [4]).

It is difficult to estimate the extent to which such practices spread in the following decades. Dicks remarks that this practice "is not generally accepted" and the sparsity of documents hints to a rather slow development. The international reception of the CPE didn't extend to its emphasis on note-taking and record keeping. In Switzerland and Germany, as far as we know, entries concerning pastoral care were restricted to short entries concerning the last rites for Catholic patients.

A new era of clinical pastoral documentation began with the emergence of outcome-oriented chaplaincy in the 1990s. It was a new paradigm of healthcare chaplaincy, one which responded to changes in healthcare generally (e.g., the introduction of the DRG [diagnosis-related group] Codes). Key to this new development was the Barnes-Jewish Hospital in St. Louis, the largest hospital in the USA state of Missouri and teaching hospital for Washington University School of Medicine. "Since 1990," Methodist chaplain and pioneer Arthur M. Lucas summarizes: "the Chaplains at Barnes-Jewish Hospital (BJH) have sought to increase their integration into and accountability with the care teams" (VandeCreek and Lucas 2001, 2). Communicating more effectively with others about spiritual care has been a cornerstone of this new approach, which entails entering the chaplain's assessments, plans, interventions, and evaluations into the medical records. The influence of this initiative is also documented in the present volume. The models presented by Brent Peery (Memorial Hermann Hospital, Houston) and by Anne Vandenhoeck (University Hospital, Leuven) have been shaped by the approach Lucas and his colleagues developed in St. Louis.

\footnotetext{
${ }^{2}$ Dicks mentions also "periodic reports, preferably written reports, to the hospital administrator, to the board of directors of the hospital, and to the church authorities under whose auspices he is serving", Dicks 1940, [5].
} 


\section{Charting Spiritual Care in Electronic Medical Records}

The emergence of the digital age is the central turning point for the genealogy we are about to trace here. The developments outlined so far achieved a new scope with the introduction of the electronic medical record (Gillum 2013). Let us briefly summarize the history of this cornerstone of digital healthcare.

Efforts to create electronic medical records (EMRs) began in the 1960s, with the promise of transferable documentation that would allow a third party to understand a diagnosis based on detailed entries, from family history to patients habits and blood analysis (Doyle-Lindrud 2015). The 1970s saw the electronic implementation of the so-called problem-oriented medical record (POMR). This system of records, designed by doctor and researcher Larry Weed (1923-2017), made the medical history of a person, his/her so-called problem list, accessible to multiple physicians. Nevertheless, it was only with the rising importance of personal computers that the breakthrough came in the 1990s. A resulting increase in transparency, portability, and accessibility to personal medical data was seen first in hospitals and then in smaller medical environments, such as doctors' surgeries. Data was then made more readily accessible to multiple actors, with the consequence that multiple actors participate in the file in a user-friendly and easy way. An increase in transparency, portability, and accessibility to personalized medical data followed up. The rise of the Internet set new standards and created new possibilities, which then led to webbased EMRs. Around 2010, the Obama administration began to push the development of EMRs in the USA, with repercussions all over the world.

While digitization was initially characterized by the simple replacement of the pen with the keyboard, web-based EMRs bring with them significant qualitative change. The intention was to collect and merge data in a patient-centered manner. Furthermore, clinical data was to be immediately available. A "location-independent" virtual application for different health processes was thus made possible.

Having first appeared in experimental projects at the turn of the millennium, web-based EMRs became more sophisticated and reliable in the 2010s. This was also when governmental healthcare organizations, hospitals, and health insurance companies began to promote and fund the development and implementation of EMRs. The further development of EMRs remains a central challenge today, for example, in Switzerland, following the 2015 legislation to implement personal electronic dossiers from 2020. Questions of security, patient contributions, big data applications, data storage and synchronization, as well as practicability play a major role in this process. Concerning EMRs "physicians also noted dissatisfaction with poor usability, time-consuming data entry, interferences with face-to-face patient care, inefficient and less fulfilling work content, inability to exchange health information" (Doyle-Lindrud 2015, 154). EMRs are also sometimes heavily criticized as instruments which make patients disappear (Hunt et al. 2017). 


\title{
4 Worldwide Distribution of Spiritual Care Records in EMR
}

As this volume shows, the worldwide integration of spiritual topics into the EMR has proceeded at an astonishing pace in recent years. To the examples collected in the contributions to this volume, we should like to add another. It comes, rather surprisingly, from a slum in Nairobi. ${ }^{3}$ In 2002 the Eastern Deanery AIDS Relief Program (EDARP) initiated electronic record keeping to meet the reporting requirements of this rapidly expanding program. In 2018, Richard W. Bauer, a Maryknoll priest, social worker, and board-certified chaplain, took office in this program with the goal of creating "a comprehensive public health intervention that includes assessment and treatment for each individual person's physical, emotional, social, and spiritual well-being and health. Like all health interventions, for quality patient care these interventions (in all domains) must be documented and shared with an interdisciplinary team." There was unanimous assent that EDARP needed to incorporate this into the system of comprehensive, differentiated patient-centered care for HIV and that this assessment needed to be documented in the EMR. It was decided, that the EDARP social workers (one at each of 14 sites) would be the staff initially trained in this methodology and intervention/screening.

\begin{abstract}
Working with our biostatistician, we concluded that we needed both qualitative and quantitative data. We incorporated the FICA ${ }^{4}$ tool and some other quantitative measures to help the social worker and interdisciplinary team better understand how a patient's individual spiritual beliefs and practices may enhance, or impede, adherence to treatment for HIV. The goal of these conversations is not for the social worker to impose their beliefs on the client, but to establish that EDARP values discussing their faith, beliefs and spiritual practices and how these beliefs may impact the individual's treatment and health. Ultimately, we hope to present (but never impose) a model of care and treatment that is about 'prayer and medicine', not, 'prayer or medicine'.
\end{abstract}

The social workers all began to implement this intervention in the second half of 2018. Richard Bauer meets them frequently to give them support and supervision and to discuss the use of this tool and their impressions regarding acceptability. Overwhelmingly, with few exceptions, patients appreciated the fact that the issue had been brought up.

I was particularly concerned with one of our sites that is in a predominantly Muslim area of Nairobi and most of our staff identify as Christian. However, the social worker in this site frequently contacted me asking how to cut off the conversations, as patients were so excited to be able to talk with someone about their faith and health that the social worker needed to contain the long conversations.

On January 1, 2019, after a couple of revisions, the tool was then uploaded into the EDARP electronic medical record. Only three of the fourteen sites were to use this version in the EMR, while the other sites continued to use the tool with written

\footnotetext{
${ }^{3}$ We thank Richard W. Bauer for all the information about this project and the opportunity to use them for our historical sketch. The quotations are taken from his personal account, with permission. ${ }^{4}$ Cf. Borneman et al. (2010).
} 
records, sharing information with other clinicians during the interdisciplinary team meetings. The main benefit of having the spiritual screening in the EMR is that all members of the clinical team (nurses, clinical officers, pharmacists, adherence counselors, and social workers) have access to the information. They don't have to repeat screenings and assessments, and they can draw on previous records, obtained from the social worker, in later clinical discussions.

It may be incidental that our historical sketch started in Egypt and ended in Kenya. We came across Bauer's initiative by accident in the context of a research project investigating the WHO's handling of the "spiritual dimension" of health, a discourse in which delegates from the southern hemisphere have played a crucial role. We regard this accidental discovery as a reminder that any future history of charting spiritual care would also have to include developments in the global south. The fact that the use of EMRs with entries on spiritual care has reached the slums of Nairobi (and most probably also other places in the "majority world") is a clear sign of the globalized character of today's healthcare. In conjunction with the ongoing digitalization of social life, the globalization of healthcare will most probably be a main driver for the future development and dissemination in this area.

\section{References}

Assmann, Jan. 2011. Cultural memory and early civilization. Writing, remembrance, and political imagination. Cambridge, MA: Cambridge University Press.

- 2012. Cultural memory and the myth of the axial age. In The axial age and its consequences, ed. Robert N. Bellah and Hans Joas, 365-407. Cambridge, MA/London: Belknap Press of Harvard University Press.

Athanasius. 1981. The life of St. Anthony. In Early Christian biographies, ed. Roy J. Deferrari, 3rd ed., 133-216. Washington, DC: The Catholic University of America Press.

Borneman T. B. Ferrell, and C. M. Puchalski. 2010. Evaluation of the FICA Tool for Spiritual Assessment. Journal of Pain and Symptom Management 40/2:163-173. https://doi. org/10.1016/j.jpainsymman.2009.12.019

Cabot, Richard C., and Russell L. Dicks. 1944 [1936]. The art of ministering to the sick. New York: The Macmillan Company.

Dicks, Russell L. 1940. Standards for the work of the Chaplain in the general hospital. http:// www.professionalchaplains.org/files/professional_standards/standards_of_practice/standards_ for_work_of_chaplain_russell_dicks.pdf.

Doyle-Lindrud, Susan. 2015. The evolution of the electronic health record. Clinical Journal of Oncology Nursing 19 (2): 153-154.

Foucault, Michel. 1997. Self-writing. In Michel Foucault, ethics: Subjectivity and truth, ed. Paul Rabinow (Essential works of Michel Foucault 1), 207-222. New York: The New Press.

Friedrich, Markus. 2007. Communication and bureaucracy in the early modern Society of Jesus. Schweizerische Zeitschrift für Religions- und Kulturgeschichte 101: 49-75.

Gillum, Richard F. 2013. From papyrus to the electronic tablet: A brief history of the clinical medical record with lessons for the digital age. American Journal of Medicine 126: 853-857.

Hart, Curtis W., and M. Div. 2010. Present at the creation: The clinical pastoral movement and the origins of the dialogue between religion and psychiatry. Journal of Religion and Health 49: 536-546.

Hendrick, Burton J. 1914. Team work in healing the sick. The World's Work 2: 410-417. 
Hunt, Linda M., Hannah S. Bell, Allison M. Baker, and Heather A. Howard. 2017. Electronic health records and the disappearing patient. Medical Anthropology Quarterly 31 (3): 403-421. https://doi.org/10.1111/maq.12375.

Myers-Shirk, Susan E. 2009. Helping the good shepherd. In Pastoral counselors in a psychotherapeutic culture 1925-1975. Baltimore: Johns Hopkins University Press.

Schutz, Roger. 1974. Kampf und Kontemplation. In Auf der Suche nach Gemeinschaft mit allen. Freiburg i.Br: Herder.

Vande Creek, Larry and Arthur M. Lucas. 2012 [2001]. The discipline for pastoral care giving. In Foundations for outcome oriented Chaplaincy. London: Routledge.

Worcester, Elwood, Samuel McComb, and Isador H. Coriat. 1908. Religion and medicine: The moral control of nervous disorders. New York: Moffat, Yard \& Company.

Open Access This chapter is licensed under the terms of the Creative Commons Attribution 4.0 International License (http://creativecommons.org/licenses/by/4.0/), which permits use, sharing, adaptation, distribution and reproduction in any medium or format, as long as you give appropriate credit to the original author(s) and the source, provide a link to the Creative Commons license and indicate if changes were made.

The images or other third party material in this chapter are included in the chapter's Creative Commons license, unless indicated otherwise in a credit line to the material. If material is not included in the chapter's Creative Commons license and your intended use is not permitted by statutory regulation or exceeds the permitted use, you will need to obtain permission directly from the copyright holder.

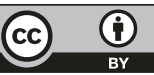

